\title{
Cidade de Deus - Refrações contemporâneas do cinema brasileiro
}

\section{Resumo}

Ao explorar as marcas (inter/intra) textuais do cinema contemporâneo, aqui são estudadas algumas questões sobre o processo híbrido/labiríntico da estrutura fílmica, diante de transversalidades sincréticas da tecnologia à estética. Nesse percurso sincrônico, elabora-se uma (des)construção (inter)subjetiva do cinema, a partir das teorias críticas contemporâneas, uma vez que estratégias discursivas manifestam-se como mecanismos conceituais da produção audiovisual. Assim, este texto apresenta uma leitura crítica sobre o filme Cidade de Deus (2002), de Fernando Meirelles e Katia Duran, adaptado do romance de Paulo Lins.

As aspirações para refletir tecnologia e estética entrecruzam variantes poéticas no cinema contemporâneo, cujo processo de criação investe, cada vez mais, em predicações estratégicas. Observo que, o contemporâneo inscreve-se como algo efêmero, inacabado, parcial e provisório, cujas estratégias discursivas são atualizadas, conforme as (inter)mediações diacrônica e sincrônica. Efetivamente, as expressão contemporânea se metamorfosea, rapidamente, como as mutações de um camaleão. Em outras palavras, a composição da informação no contemporâneo apresenta-se, estrategicamente, de maneira complexa, i.e., elenca uma série de argumentos flexíveis, impactantes, dinâmicos, fragmentados.
Neste contexto, as estratégias são planejamentos que promovem um conjunto de articulações dos enunciados técnicos, co-habitando uma perspectiva estética na

estruturação fílmica. Desta forma, investigo algumas inquietações, que julgo pertinentes: Como o cinema configura traços contemporâneos? O filme é realizado para quê ou para quem? Quais são as implicações teóricas intrínsecas nos interstícios da imagem e do som que envolvem o campo do cinema? E, ainda, como perceber os enlaces dos enunciados audiovisuais que apontam a trajetória de um duplo eixo - técnica e estética? A partir da noção de contemporâneo, poderia ser desenvolvida uma poética que demonstre as alteridades subjacentes do cinema brasileiro?

Constituído de um lugar possível de diferentes estratégias discursivas, os meios cinematográficos parecem enunciar uma explosão de dispositivos instrumentais, capaz de reiterar e (re)configurar as mediações contemporâneas tanto na arte quanto na comunicação. O cinema é visto/lido como um sistema complexo, que agencia as múltiplas modulações entre arte e comunicação, uma vez que o processo de criação, produção, realização, distribuição, circulação e recepção estão presentes nesses sistemas. Desta forma, arrisco observar um desdobramento de duas etapas, embora elas não se estancam:

1) os procedimentos de realização que instrumentalizam a elaboração fílmica, em que os suportes tecnológicos implementam os efeitos estéticos; e 
2) a participação do espectador diante de sua ação perceptiva, as quais integram um processo de recepção, interação, conexão, entre outras.

Uma possível noção de cinema, assim, articula uma síntese de enunciações plausíveis, que negocia as circunstancialidades de determinadas refrações. A fusão de arte e comunicação inscreve-se a partir de uma gramática audiovisual, a qual enuncia evidências semânticas que se complementam na flexibilidade de elementos morfológicos e sintagmáticos. Essa gramática (da imagem e do som) comporta os (inter)câmbios dos produtos culturais, equacionada pelas manobras técnicas e estilísticas no filme contemporâneo. A dinâmica da representação contemporânea, de modo geral, apresenta-se diluída em um campo de intertextualizações de saberes e vivências, tendo em vista a experimentação dos caminhos propostos, tanto sob os aspectos dos conceitos, das metodologias, das práticas quanto dos suportes. $\mathrm{O}$ resultado desses encontros são as formações de produtos audiovisuais, atentos aos textos socioculturais.

Evidentemente, há um rigor metodológico para eleger os critérios que incidem na expressão desses produtos culturais. Cada vez mais as agências de negociação entre arte, comunicação e sociedade ressaltam "novas/outras" discursividades, cujas implementações podem ser observadas a partir de alteridades e diferença, sobretudo nas narrativas do cinema contemporâneo. As incorporações de redes de conversações estão atreladas ao campo dos meios

audiovisuais e digitais (cinema, TV, vídeo, computador) como uma recorrência discursiva apostada pelas teorias críticas contemporâneas.

A abertura que as tecnologias atuais propicia ao cinema é um dado fundamental para pensar as representações emergentes. De modo não-linear, o formato dessas representações se multiplica, pois a (des)referencialidade se fragmenta, entre a manifestação de um objeto e sua leitura. O espaço hipermidiático (da estrutura narrativa e do objeto explorado), que o universo digital investe, requer novos desafios, em que os argumentos (des)materializam-se em suas (de/trans)formações, paulatinamente. Dito de outra forma, a atualização da linguagem fílmica (audiovisual), hoje, toma-se refém dos recursos técnicos e conseqüentemente estilísticos, visto que a tecnologia possibilita "novas" experimentações, tanto na realização quanto na recepção. Essa premissa se faz presente, também, nas (des)construções cinematográficas brasileiras, as quais se operacionalizam estrategicamente uma condição adaptativa.

No cinema brasileiro, essa síntese camaleônica de experimentações contemporâneas não é diferente. Assim como elevar alguns aspectos socioculturais para a tela implica (re)pensar a expressão dos elementos elencados para além de uma dimensão antropofágica, tendo em vista o panorama eclético da cultura nacional. Há uma efervescente expressão cinematográfica, no Brasil, com o chamado cinema da retomada. Essa marca diacrônica do cinema da retomada abre um novo fôlego mercadológico, que viabiliza a projeção do filme brasileiro. Também, a retomada ocorre num momento em que o cinema efetiva um diálogo com as novas tecnologias, o que provoca uma (des)construção prática e teórica sobre o processo de criação fílmica. As novidades técnicas e estéticas surgem como ressonâncias do desbravamento da floresta tropical. O panorama do cinema brasileiro está sendo alargado para as fronteiras internacionais, que observa a passagem inusitada dessa produção cultural.

Ao refletir sobre as refrações contemporâneas no cinema brasileiro, o presente ensaio objetiva argüir acerca das transversalidades (sincréticas) que conduzem as estratégias discursivas, sobretudo no filme Cidade de Deus (2002), de Fernando Meirelles e Katia Duran. Eminentemente, aponto dois momentos 
específicos para refletir esta cinematografia, tendo em vista as quatro indicações para a premiação do Oscar/2004 - nas categorias direção, fotografia, montagem e roteiro adaptado. Este fato coloca em discussão o percurso do processo de criação do cinema hoje, de acordo com a relevância tecnológica dessas categorias. Por outro lado, o impacto que o filme causou, em certa medida, um mal-estar conceitual para alguns intelectuais (Bentes, 2000), ao provocar um debate significativo sobre o uso do tema da "derrocada social" na produção audiovisual brasileira contemporânea.

Visto sem antolhos, ambos momentos distintos parecem polemizar, ainda mais a capacidade de refrações conceituais, diante da contribuição deste filme para o desenvolvimento do cinema brasileiro. Em termos mercadológicos, esses dois momentos colocam o projeto de Meirelles e Duran em um lugar de destaque na mídia nacional e internacional, promovendo acirrados contextos discursivos, que (de)marcam os detalhes de acabamento técnico e afinamento estético da película. Essa possibilidade de abrir fronteiras indica a capacidade criativa e reforça a dimensão técnica e estética de um projeto fílmico ajustado com a demanda do mercado.

Ainda que esse texto possa perpassar um viés sociológico, paradoxalmente ressalvo que, tento afastar-me dessa vertente para adentrar à prerrogativa das articulações conceituais. Torna-se oportuno, portanto, refletir sobre os "novos" olhares do cinema brasileiro, que transita pelo território da desigualdade social, sem o comprometimento, exclusivamente, político. $\mathrm{O}$ projeto fílmico de Cidade de Deus não se reveste de um escopo que argumenta a denúncia social, embora contenha em si o tema da exclusão. $O$ filme emerge-se como mediador da cultura dos morros cariocas. Na conversa dos personagem Berenice e Cabeleira surge um momento enigmático em que: "malandro não ama, malandro sente desejo. Malandro não fala, malandro manda uma letra. Malandro não pára, malandro dá um tempo". Nesse ato decrépito, as diferenças de contexto, políticas e estéticas parecem distantes (porém não aniquiladas) do manifesto "estética da fome", escrito por Glauber Rocha, em 1965.

Orquestrado por uma direção que demonstra profundos conhecimentos da gramática cinematográfica, Cidade de Deus ultrapassa uma tentativa de retratar a realidade brasileira por uma ficção visceral, ao articular os efeitos técnicos e estéticos, mas não mesmo pontual com a ética. Deste ponto de vista, a performance da degradação social na película não pode e nem ser deve ser acusada como uma banalização da violência. Seria inconsistente e principiante medir o nível idiossincrático da subjetividade, pois o filme renova o cinema brasileiro quando coloca em evidência um turbilhão de poéticas contemporâneas.

\section{Desdobramento da refração}

Cidade de Deus pode ser desdobrado pela suas refrações técnicas e estilísticas. Diante desta suposição, o filme acolhe uma saga urbana, ao acompanhar o crescimento do conjunto habitacional Cidade de Deus. Nessa arquitetura audiovisual, a experiência humana aparece como um recorte sincrônico ao tematizar a miséria e a violência no Brasil. A narrativa fílmica se desenvolve pelo impacto de cenas violentas, atreladas ao dispositivos eletrônicos e digitais que expõem os fatos de modo impactante. No deleite desse embrionário movimento sincrético de tema, técnica e estética, o filme ressalta um universo marcado, pontualmente, por assalto, droga, vingança, entre outros delitos. Essa inventividade notória aproxima o projeto fílmico de uma recorrência (inter)subjetiva aos possíveis conceitos do neo-realismo italiano: a filmagem em cenários reais e o uso 
de um elenco de intérpretes do povo indicam a linhagem do tema à um prognóstico da emergência social. A adesão desses elementos inscrevem uma aproximação de fronteiras contaminadas por ficção e realidade.

Há um protagonista, Wilson Rodrigues, mais conhecido como Buscapé, que de maneira clássica, narra a história dos diversos tipos de malandragens do morro. É um menino pobre, negro, sensível, porém amedrontado com a idéia de se tornar um bandido, mas também, esperto o suficiente para se resignar dos problemas enfrentados. $\mathrm{O}$ personagem cresce num ambiente de bastante miséria e violência, transitando num tênue fio que divide a malandragem e a vida cotidiana da favela. Mesmo sentindo que todas as chances estavam contra ele, descobre que pode ver a vida com outros olhos - a fotografia.

Com a câmera fotográfica, ele (re)vela um registro figurai da malandragem da favela. Trabalhando na distribuição de jornal, tem a chance de fazer a ponte entre a caverna (do submundo) e a cidade (o jornal). Enquanto narrador, é ele quem determina e enuncia os fatos principais do filme. O espectador torna-se refém do depoimento de Buscapé e acaba conhecendo o desenrolar da narrativa fílmica a partir de sua perspectiva. É, na verdade, um mundo sem redenção, aparentemente condenado por uma violência infinita. Diante do estado de projeção/identificação, uma idéia clássica no universo do cinema, depara-se a aproximação do espectador ao protagonista. Neste testemunho, o público tenta absorver a complexidade de situações brutas, que apontam um ambiente refratado, tecnicamente, em diferentes histórias que se cruzam e se entrelaçam.

A condição adaptativa de eleger o olhar de Buscapé como um ponto de vista para narrar o filme e (re)configurar a noção de refração como uma estratégia discursiva, cujas propriedades propagam os enunciados em diferentes instâncias. Refratar a informação do narrador implica abrir variantes, que empregam múltiplas e plurais incidências. $\mathrm{O}$ ato de refração amplia as variantes de um objeto (inter)textual. Como um efeito caleidoscópio, próprio da linguagem do cinema, a dinâmica das mudança de velocidade, angulação, iluminação providenciam a polarização e o embatimentos dos argumentos. Isso pode ser observado nas repetições dos argumentos que são visto e revistos por vários ângulos, em diferentes momentos da narrativa.

Essa (des)construção do enredo joga com o espectador pelas suas passagens (inter)cambiantes, pois algumas cenas se repetem por diferentes momentos para explicarem os fatos, como bifurcações de caminhos possíveis. Ao reiterar os instantes da cena, o procedimento narrativo justifica a decisão tomada pelo personagem, como se fosse possível suplementar as informações. Nessa (dis)junção, o hibridismo da refração emerge-se na manifestação de um para além de e/ou quase que instâncias discursivas que diluem a possibilidade de uma representação (Bhabha, 1998). O conjunto dessas refrações no filme provoca um procedimento de deslocamento e condensação de referências poéticas.

As refrações contemporâneas no cinema instigam diferentes abordagens. No tratamento dessa cultura da intransigência, recomenda-se cuidado com a descrição do submundo. A obscuridade do estranhamento arrasta o filme para mergulhar nos desafios humanos. Sem reservas ou maldade, a situação de morte, vingança e violência é assistida de frente, junto à promessa de obstáculos. Estar diante de um problema implica presenciar uma "realidade" crítica: um saber sem sabor. Testemunhal.

Outro elemento revelador que tange o clímax de Cidade de Deus está no elenco que vive no filme uma possível "realidade", a qual lhe é muito próxima. Essa proximidade faz com que a atuação, por vezes, possa remeter a uma idéia de documentário, ou melhor um "docudrama". Com um 
extenso elenco, cuidadosamente trabalhado, o filme corresponde ao empenho de preparação e direção de jovens atores não profissionais de diversas comunidades carentes do Rio de Janeiro, cujos resultados indicam entre eles: Alexandre Rodrigues como Buscapé, Leandro Firmino da Hora como Zé Pequeno, Phellipe Haagensen como Bené, Jonathan Haagensen como Cabeleira.

Destaque especial para a interpretação feroz de Zé pequeno. Personagem audacioso, vulgar, crítico e violento. Quando criança era Dadinho, mas quando cresceu e ganhou maior idade passou a imperar na favela como Zé Pequeno. Ao realizar ações inumanas, capaz de matar até a família e os amigos, o personagem comete assaltos e crimes inescrupulosos. Carrega consigo a dor da miséria e o desejo constante de poder na favela. Porém, a morte ronda o sujeito. Intenso na sua performance irracional, Zé Pequeno parece responder externamente algumas possíveis frustrações pessoais: não tem amigos além do Bené, que morre no baile; não tem garotas e não sabe dançar. A transferencia desses fracassos remedia-se com os acessos súbitos de violência. Contra o mundo e contra todos, Zé Pequeno tem sede de vingança da vida. Suas atitudes odiosas são degenerativas como suas feições obscenas. Resultado: os policiais tomam-lhe o seu dinheiro, e alcança a morte com tiros nas costas, executado pelas crianças que ele mesmo deu as armas, mas não prestou atenção que eram garotos vingando a amizade deles com Sandro Cenoura.

O filme demonstra personagens que não tem nada para perder. São explosivos e destituídos do medo, conforme a fita parodia a máxima de Glauber: "pra ser bandido não basta ter uma arma na mão, precisa ter uma idéia na cabeça”. Essa sinalização irônica cita uma das fonte do Cinema Novo e transpõe um diálogo que enfoca a atualização do cinema. Em Cidade de Deus a barbárie contamina o contexto narrativo ao propor mutações radicais, no desejo de transformar a aridez das cenas à exuberância extrema, e tomarse uma dimensão utópica (não lugar).

Elabora-se, assim, as (de/ trans)formações de um não-lugar, que sincreticamente dinamiza-se para além de um "outro-lugar", alternado/ diferente de uma localização cristalizada de espaço-tempo. Do corte à montagem, a emenda de imagens distintas cria um ritmo narrativo adequado ao enfoque proposto pelo filme. Nessa extensão emerge um entre-lugar - espaço de (inter)subjetividade. Esse último configura-se pela (des)construção dos enunciados contemporâneos, segundo os estudos culturais de Homi Bhabba (1998). É algo que discute, inova e rompe as marcas de fronteira, de limite das "coisas". O entre-lugar (des)regula a compreensão de centro, periferia e arestas, em que objeto e signo deslizam-se pelas condições adaptativas. Nesta perspectiva, não há dentro (in) ou fora (out), porém uma íntima relação versátil que se (re)apropira das argumentações do sistema hegemônico. Os interstícios expostos pelo entre-lugar subvertem o sistema, diante das brechas, das fendas. São ressonâncias de estratégias discursivas que promovem possíveis aberturas coerentes na condução cinemática.

Retomando ao filme, talvez, o grau de invenção em Cidade de Deus anuncia uma produção atualizada, em que fotografia, montagem, som, edição e direção obtêm seu reconhecimento no momento da exibição para o espectador e é confirmado nas premiações de festivais. Observa-se a relevância técnica do filme acoplada a um efeito estético compatível à temática. Além disso, acompanha o desenvolvimento e a influência digital que se encontra o cinema contemporâneo. Um hibridismo de linguagens e códigos transversaliza diferentes dispositivos e suportes, nos quais a película, o digital e o vídeo se misturam e se completam, ao propor resultados eficazes.

Do ponto de vista técnico, esse movimento ambíguo de (dis/ 
con)junção elabora um grupo de suturas que pode ser visto/lido como um marco por colocar em debate - e de certo modo em crise - o próprio cinema brasileiro. Da ética à estética, a questão equacionase nas premissas abordadas no início deste texto: A partir da noção de contemporâneo, poderia ser desenvolvida uma poética que demonstre as alteridades sub-jacentes do cinema brasileiro?

Diria que, o cinema atual apresenta-se sob uma complexidade, em que variados estilos, gêneros e linguagens se confluem. Distante do escopo para inaugurar um conceito, um manifesto ou um tratado estético do cinema brasileiro, Cidade de Deus tira o espectador de sua imobilidade "passiva". Influenciado pela publicidade e pelo vídeo, essa película traz uma linguagem urbana, em que a edição não-linear propicia a sobreposição de janelas e/ou quadros numa mesma tela, simultaneamente; intermediações, passagens e/ou fusões de imagens sobrepostas, fotografias alteradas por luz, ângulo, textura e/ou contrate; entre outras recorrências. Iminentemente, também distante de querer provocar algum estardalhaço sobre a miséria.

\section{Da técnica à estética}

Ao considerar as estratégias discursivas apontadas pelo filme Cidade de Deus, observo uma estética polifônica que arrisca-se na contaminação de linguagens e dispositivos. A película do cinema se tece diante de recursos plásticos da arte e da comunicação. Essa assimilação de técnicas e estética se expande com propósitos cinematográficos, diante de singularidades e ajustamentos. A experiência audiovìsuál, aqui, relata com coragem a vida da favela, por meio de retalhos (fatos, dados) alinhavados e vigorosos. Um ponto de vista agudo e peculiar ressalta reparaçõ̃ẽs virulentas do mecanismo da exclusão social.

A possibilidade de compartilhar as áreas da produção audiovisual atinge a (inter)mediação recorrente de publicidade, televisão, vídeo, cinema, internet, entre outras. Esse conjunto de diferentes áreas investe em contaminações complexas, capazes de ambientar significativas mudanças no processo de criação fílmica. Assim, a convergência das mídias contribuem para uma "nova/outra" lógica da comunicação (audiovisual, eletrônica, multimídia, digital), a qual se denomina cultura midiática (Garcia, 2003, p. 2941).

O prólogo de Cidade de Deus se estende entre flashes visuais de uma faca, sendo amolada na pedra, como na publicidade: um tempo cortante, elíptico, pontual. Vultos dessa cena inicial sobressaltam-se como um pulsar (piscante), ao arrebatar um diálogo com a linguagem videográfica. Os cortes rápidos da cena promovem fragmentos curtos e imediatos que se traduzem entre o videoclip e a publicidade. A competência publicitária, neste caso, aponta para uma síntese narrativa, ou seja, a economia de expressão com a máxima força de informação. Esse fascínio desenhado pela sedução e persuasão da imagem publicitária aposta na fixação do target (alvo) e engorda o entretenimento do cinema numa assinatura estética "tecnologizada", a qual pode ser contemplada na esteira do consumo "inerte": preso ao desejo.

Se nesse caldeirão, logo no início do filme há essa confluência de publicidade, vídeo e TV, observa-se que a utilização dos recursos técnicos no filme absorve um movimento (inter/ trans)textual discursivo. Nesse construto, as estratégias discursivas elaboram as mediações dos argumentos sincréticos. A habilidade na condução frenética dessas situações flerta com uma vertente ousada. Soluções estéticas se fundem, saltam à vista, enfeitam o relato e esbanjam a predileção pelo requinte imagético das cenas. No vácuo da publicidade, os recursos cênicos e narrativos do filme são, técnica e esteticamente, agrupados e distribuídos de maneira fluente, em que a contenção adequada desses elementos ajusta-se em uma 
vetorização exclusiva para a ocorrência da cena. Escolher/selecionar a arrumação que operacionaliza a dinâmica da narrativa requer um esforço atento aos efeitos precisos do filme. Em outras palavras, a direção de Cidade de Deus trabalhou uma aglutinação contundente de aspectos técnicos e estéticos, que relacionam os encaixes necessários para instaurar um ar de experiência inédita ao espectador.

O efeito visual da textura de um azul saturado pela lente da câmera ou pela pós-produção, confirma essa aproximação enunciativa do vídeo. Observa-se a distinção entre os pontos eletrônicos na varredura de um monitor de TV e a malha visual opaca, quase diáfana, de uma película. Em outro instante, a entrada do samba no ambiente acompanha a caça da galinha, a qual pode ser vista, em primeiro plano, correndo entre as vielas da favela. Essa perseguição animalesca redimensiona bandidos e policiais, já que, neste filme, não há mocinhos, herói ou final feliz! O som cria ritmo à cena e desperta o espectador, ao acusar estímulos na tensão do abismo social e a farra apresentada pela fita Começou!

Uma trilha especial aposta num som instrumental e incidental: vibra de modo orquestrado, épico, emocional. $\mathrm{O}$ tom musical aponta uma melodia entre hip-hop, samba-reggae, funk, (clima carnudo), compilado pelo ritmo de uma black music brasileira. O efeito sonoro parece divergir da própria glamourização da crueldade que o filme possa emoldurar. Esse menu inclui o contato da trilha com o enredo e a edição das imagens. Um contraste de idéias técnicas que aborda, esteticamente, a quebra dos entrechoques temáticos do filme.

A fuga da galinha é um mote para percorrer e documentar as vielas da favela, como quem explora um labirinto recheado de bifurcações díspares. Essa introdução da narrativa, como um ato de iniciação, indica a proposta fílmica que desliza sua discursividade entre o grotesco, o bestiário, o baixo-corporal, o nefasto. A impressão de primitivo se acoberta pela instauração diabólica do selvagem em cena. Diria que é um filme bruto, tipicamente, masculinizado, demoníaco, pois o contexto narrativo

demonstra os enfrementos

masculinos, colocando a mulher apenas como elenco distante, coadjuvante.

O ambiente é o seu "verdadeiro" protagonista, em que a narrativa aborda situações que acontecem de fato. São histórias reais, incorporadas pela dinâmica da luz do cinema. Cidade de Deus é o nome do bairro que dá o título ao filme. Como sistemática da direção torna-se um ato de ruptura que (des)constrói o muro entre centro e periferia, uma vez que elimina a possibilidade de pensar o mundo fora da Cidade de Deus. Conforme descreve sua sinopse, o principal personagem desse filme é o lugar uma favela que surgiu no começo da década de 1960, e se tornou uma das regiões mais perigosas no subúrbio do Rio de Janeiro. A trama se desenvolve em três períodos: inicia em 1960, passa pela década de 1970 e termina na de 1980. Neste contexto, há um vácuo no filme que interliga a ficção à realidade, ao retratar o crescimento do crime organizado na periferia.

O embatimento tecnológico proposto por Cidade de Deus incentiva com perspicácia a produção do filme brasileiro, uma vez que seus efeitos digitais provocam vertigens, as quais deixam marcas impressas. Essa disponibilidade técnica garante um estado híbrido de deslocamentos que convocam o público à experienciar o inesperado, o inevitável. $\mathrm{O}$ filme conduz uma estratégia discursiva, ou seja, os aparatos tecnológicos empregados surpreendem o modo de narrar as armadilhas "tiranas" da fita.

O roteiro, adaptado da obra de Paulo Lins, culmina num tecido discursivo complexo. Efetivamente, essa complexidade está na construção de uma linguagem ágil, dinâmica e objetiva, que de modo eficaz traz soluções criativas, descarta o 
imaginário da ficção e se aproxima da realidade da favela. A eficiência se traduz, também, pelas articulações na montagem, quando a fotografia e edição se fazem presentes, junto com o movimento de câmera que conduz uma relação desenfreada entre elipses de espaço e tempo. Cidade de Deus flui de modo hábil, com avanços e recuos no tempo.

A câmera gira 360 graus, num travelling interno, para deslocar o tempo dos anos de 1960 aos de 1980. Neste efeito o espectador tem o campo de visão do espectador é Buscapé, que está no centro desse eixo circular. Como a invenção da roda que faz o mundo girar, verifica-se uma transposição contundente desse descolamento que (de)marca a proposta estética da direção, calcada nos aparatos tecnológicos. Neste recurso técnico, mais de uma vez aplicado, o espectador observa a posição do protagonista estilizado, metaforicamente, como um duelo de armas. O que o espectador presencia na tela é uma mira no horizonte, e torna-se, portanto, agente e vítima, arma e alvo. Tudo ao mesmo tempo, em foco: são vidas simples e rasas revestidas de um aprisionamento testemunhai, o qual intimamente se acopla - personagem e espectador. Nesta disputa de posições, é a própria imagem de cada um que se reflete no duplo espelho da rotina violenta de chacinas - o sangue disputado pelo ponto de drogas.

A sobreposição de imagens transmuta espaço e tempo numa perspectiva de ações, iluminação, filtros e cores. A textura da cena se apropria da materialidade técnicas para criar um clímax e se fazer substância. Ainda neste giro de 360 graus da câmera o som do relógio sobrepõe um mesmo estado sonoro acelerado, que se recobre na fusão de diferentes

imagens, contextualizadas pela estrutura narrativa. Essa recorrência técnica concilia a passagem eminente dos fatos, cujo virtuosismo diegético se vê cumprido.
O filme de Meirelles e Duram penetra num território de possibilidades discursivas, até então, pouco explorado em termos de tecnologia pelo cinema brasileiro. O cinema da retomada investe nessa diretriz. A vetorização da narrativa (des)construída pelo roteiro adaptado transforma a capacidade de mediação do filme em uma retórica programada de subterfúgios técnicos e estéticos. O filme assina um enredo comprometido com os entrecruzamentos técnicos da trama, em que os (des)encontros dos personagens e suas ações colidem com o envolvimento do público. A fusão desse contexto rebate as cenas como efeitos de espelho, que desafiam uma subversão e desconsertam o posicionamento quase que "confortável" do espectador.

Nesse ambiente de trocas, o tema construído pela direção (re)ordena os artifícios de uma crítica narrativa e plástica sobre a linguagem

cinematográfica. O desafio está na intenção desses artifícios, que podem ser vistos/lidos como complementos pontuais da cena. De modo geral, os efeitos da linguagem cinematográfica em Cidade de Deus traduzem o percurso gerativo desdobrado do código verbal ao não-verbal. Essa (des)construção do enredo joga com o espectador pelas suas passagens (inter)cambiantes, pois algumas cenas se repetem por diferentes ângulos para explicarem os fatos, como bifurcações de caminhos possíveis. Ao reiterar o momento da cena, o procedimento narrativo justifica a decisão tomada pelo personagem, como se fosse possível suplementar as informações.

Como um depoimento poético, Cidade de Deus é de vigor espantoso com sua competência narrativa, sobretudo ao arrebatar o relato e o debate da desigualdade social. O roteiro testa os limites do cinema e retrata uma situação complexa de nevralgias sintomáticas. Em certos momentos, a narração seduz o espectador pela articulação cometida, que aos poucos introduz personagens e ações, como quem conhece, controla, 
domina a situação, efetivamente, testemunhada. Um formato enfeitado de gracejos poéticos, rítmicos, os quais evitam descrever a pontualidade de determinados momentos impactantes.

Uma adaptação roteirística enxuta e engenhosamente construída, ainda que exposta na esteira americanizada, torna-se um trunfo potente, pois as cenas estão extremamente entrelaçadas, sem deixar arestas que o espectador possa questioná-las. De fato, observa-se um roteiro coerente com uma montagem ágil e bem concebida. Um conjunto de idéias amarradas documentam a estrutura fílmica, em que a consistência do enredo se subverte ao destino dos personagens, diante de estratégicas enunciativas.
Ao se reapropriar do sistema hegemônico, ou seja, a posição americana (globalizada), para não dizer hollywoodiana, o filme Cidade de Deus aposta na diversidade cultural, quando se reveste por uma técnica cinematográfica precisa marcada pela estética de bons efeitos especiais e roteiro estruturado, os quais se afinam com uma fotografia requintada e uma edição perspicaz. Diante disso, o desencadeamento da narrativa não sofre turbulências que retiram da dramatização sua leveza, pelo contrário, destaca uma preocupação com acertos técnicos e estéticos. Esses acordos investem um em rebuscamento técnico ou estético próprio da criatividade, eminentemente, constituído pela cultura brasileira. Será que há algum mal nisso?

\section{Bibliografia do Artigo}

BENTES, Ivana. Da estética à cosmética da fome. Conferência na Universidade de Oxford, Inglaterra, em outubro de 2000.

BHABHA, Homi K. O local da cultura. Belo Horizonte: Editora UFMG, 1998.

GARCIA, Wilton. Cultura midiática: perspectivas contemporâneas. In:

NOJOSA, Urbano e GARCIA, Wilton (Orgs.). Comunicação \& tecnologia. São Paulo: Nojosa edições, 2003.

HUTCHEON, Linda. Teoria e política do corpo. Belo Horizonte: editora UFMG 2000 .

MASCARELlO, Fernando. Cidade de Deus: crítica e público. In: CATANI, Afrânio Mendes et all (Orgs.). Estudos SOCINE de cinema. Ano IV. São Paulo: Panorama, 2003.

\section{Filmografia}

MEIRELLES, Fernando e Katia Kadun. Cidade de Deus, 35mm, 130 minutos, 2002. 